\title{
Natural Superdisintegrants for the Formulation of Orally Disintegrating Tablets
}

\author{
Femi Joseph $^{1}$, K. Premaletha ${ }^{2}$ \\ ${ }^{1}$ Final Semester, M.Pharm Student, ${ }^{2}$ Professor, \\ Department of Pharmaceutics, College of Pharmaceutical Sciences, Govt. Medical College, Kannur, Kerala \\ Corresponding Author: Femi Joseph
}

\begin{abstract}
Oral route is the most favoured and preferred route for the administration for most of the dosage forms because it offers so many advantages over other routes of administration. Sometimes the oral route is associated with a problem called dysphagia. This condition can be seen in a population of paediatric, geriatric, patients with neurological problems, bedridden patients and so on. In order to overcome such a problem orodispersible tablets will be a better choice, because it will disintegrate within seconds when comes in contact with saliva. Natural agents offers so many advantages like nontoxic, easy availability, low cost, biocompatible and biodegradable in nature over synthetic agents. This superdisintegrants will cause the increase in drug release and decrease the disintegration time. This natural superdisintegrants will be a good option for the preparation of ODTs.
\end{abstract}

Keywords: orodispersible tablets, natural superdisintegrants, advantages, dysphagia

\section{INTRODUCTION}

Most of the dosage forms are administrated through oral route, which is most favoured and popular one. It becomes most preferred route of administration because of the advantages provided by oral route such as safest, convenient, avoidance of pain and better patient compliance etc. Among the dosage forms, tablet is one of the common and preferred one. But in some situations, this route may be associated with a problem of dysphagia (difficulty in swallowing). This problem is mainly seen in a patient population of paediatric, geriatric, patients with neurological problems, bedridden patients and so on. This difficulty led to the discovery of a novel dosage form known as or dispersible tablets. These tablets will get disintegrated quickly in the mouth within few seconds when it comes in contact with saliva. Disintegrants are the substances which incorporated into the tablet formulations to increase the break-up of the compressed mass into the primary particles, in order to facilitate the dissolution or release of the active ingredients when it comes in contact with water. They help for the moisture penetration and dispersion of the tablet. Nowadays superdisintegrants are developed to enhance the disintegration processes. They will be physically dispersed within the matrix of the dosage form and when the dosage form is subjected to the wet environment it will begin to expand. At lower concentrations these agents are more effective with higher disintegrating efficiency and mechanical strength. The nature of the particles is generally small and porous, so the presence of superdisintegrants in or dispersible tablet will help the disintegration of dosage form quickly in the mouth followed by dissolution process. Disintegration is an essential step for achieving fast drug release. The disintegrants should be the reason for the tablet to disrupt, not only to the granules, but to the powder particles. The disintegrating function will be occurred if it has the ability to interact strongly with 
water. There are different types of superdisintegrants based on its origin. The agents from the natural origin offers more advantages over synthetic origin. It includes safe, economical, biodegradable, provide nutritional supplement, nontoxic, nonirritant etc ${ }^{(1)}$.

\section{Orodispersible Tablets - Ideal Properties}

- It should be disintegrated within a matter of seconds.

- Easy to be administered.

- It should provide rapid dissolution and adsorption in the oral cavity.

- No need of water to dissolve.

- It should be less fragile and should possess its hardness.

- It should have less sensitive to the environmental conditions ${ }^{(2)}$.

\section{Merits of Orodispersible Tablets}

- They are very safe and easy to administer.

- It provides fast action and will be rapidly absorbed from the mouth.

- The tablets should not require water to be swallowed.

- These are very convenient for the patient population who finds difficulty in swallowing.

- It provides improved palatability.

- No need of costly packaging, hence very economical.

- Bioavailability of the drug will be improved due to the pregastric absorption.

- Less doses are required for such formulations ${ }^{(3)}$.

\section{Demerits of Orodispersible Tablets}

- It must be kept in dry place, if it is hygroscopic in nature.

- It may possess the fragile nature, effervescence granules properties.

- It may cause unpleasant taste in mouth, if not prepared properly ${ }^{(4)}$.

- Types of Superdisintegrants

- There are mainly two types,

- Natural superdisintegrants

- Synthetic superdisintegrants

\section{Superdisintegrants-Selection Criteria}

- It should possess good mouth feel.

- It should have the ability for the poor formation of gel.

- It should have higher hydration capacity.

- It should not cause any formation of complexes with drugs.

- It should be compatible with all other excipients.

- It should provide good flow properties $^{(5)}$.

\section{Superdisintegrants-various Mechanisms}

The following are the mechanisms

by which the tablets are broken into small particles.

- Swelling action

- Wicking (porosity and capillary action)

- Heat of wetting

- Chemical reactions

- Deformation

- Particle repulsive force

- Enzymatic reactions

\section{Swelling}

It is the mechanism which shown by disintegrants. When the disintegrants comes in contact with the medium it starts to swell and cause breaking of tablets. Low porosity will lead to sufficient swelling force to be exerted.

\section{Wicking (porosity and capillary action)}

Some disintegrants will produce its action through porosity and capillary action. When the tablet exposes to the medium the aqueous medium will penetrate to the tablet and will replace the adsorbed air on the particles. It will lead to the weakening of the intermolecular bonds present in the tablet and breaks the dosage form into particles.

\section{Heat of wetting}

The disintegrants with exothermic properties will cause disintegration action when it gets wetted there will be creation of localized stress due to capillary air expansion. This mechanism is shown by few disintegrants. 


\section{Chemical reactions}

Sometimes the disintegration action will be due to the liberation of $\mathrm{CO}_{2}$ gas. It occurs when tartaric acid and citric acid(acid) react with bicarbonates or alkali metal carbonates (base) in the presence of water. Hence, these reactions are also known as acid base reaction. There will be a production of pressure within the tablet, which causes the disintegrating action of the tablet.

\section{Deformation}

During compression, shape of disintegrant particles will be distorted and the particles then returned to precompression shape on wetting process. It will cause the size increasing of the deformed particles and resulting in the breaking of tablet.

\section{Repulsive force of particles}

This mechanism will be shown by the tablets with non- swellable disintegrants. When the tablet exposes to the medium, the medium will penetrate through the hydrophilic pores and a starch network will be created. There will be hydrogen bond breaking occurs. Electric repulsive forces among the particles will lead to the disintegration process.

\section{Enzymatic reactions}

The enzymes which are pre present in the body can also act as disintegrants. These will cause lack of binding action of the binders in the tablets and resulting in disintegration ${ }^{(3)}$.

\section{Natural agents for orodispersible tablets}

There are several substances obtained from natural origin. Nowadays the use of natural polymers is increasing, because of the advantages offered by these substances over synthetic. Safe, economical, nontoxic nature, nonirritant, easy availability and ability for chemical modification etc are the main advantages of natural agents. These agents usually used in floating system due to the targeted distribution of drug in GIT, i.e., stomach.
Different kind of superdisintegrants is available from our natural sources ${ }^{(\mathbf{6})}$.

\section{Natural Superdisintegrants-Advantages}

- Biodegradable in nature: The disintegrants are biodegradable in nature, because it is obtained from natural resources.

- Less cost: The cost for the production is less when compare with synthetic materials.

- Increased availability: The areas where wide range of plants are there, production of the pharmaceutical excipients like gum and mucilage's will be high.

- Biocompatible in nature: These substances are of repeated polysaccharides of sugar.

- Good acceptance by public: the chances of getting adverse effects are less ${ }^{(7)}$.

\section{Commonly used natural superdisintegrants}

$>$ Agar: It is seen in yellowish or grey or colourless with a taste of mucilage. It is in the form of dried gelatinous material taken from different species like Gelidiumamansii, Gracilaria and also from Pterocladia (red algae). Agar consists of polysaccharides such as agarose and agaropectin. Former one is the reason for gel strength, and high gel strength makes it as a disintegrant for the formulation of orally disintegrating tablets ${ }^{(\boldsymbol{8})}$.

$>$ Pectin from mango peel: Pectin, which is a hydrophilic colloid made up of a group of heteropolysaccharides. Even though the pectin cannot be used to anticipate superdisintegrant behaviour, but its high swelling index and biological fluid solubility, makes it to be used to produce orodispersible tablets ${ }^{(9)}$.

Chitin and chitosan: Chitin can be found in the shells of crabs and shrimp. In contrast to chitosan, it comprises an amino group that is covalently connected to the acetyl group. Chitosan is made by deacetylating chitin, a 
structural component of crustacean exoskeletons (crabs and shrimps) and fungus cell walls. Chitosan looks to be superior to corn-starch as a disintegrating agent and is suited for usage as a super disintegrant in tablets (10),(11)

Soy polysaccharide: It is also one of the superdisintegrants of natural origin. It is obtained from soy beans. It consists of high molecular weight carbohydrate polymers such as xylose, galactose, mannose, and arabinose. It acts as a superdisintegrant in the direct compression of tablets ${ }^{(\mathbf{1 2})}$.

Guar gum: It is taken from the endosperms of Cyamopsis tetragonolobus belongs to the family Leguminosae. It's made up of galactan and mannan units through glycoside linkages. It can be used in pharmaceutical field like disintegrant, binder, stabilizing, thickening and suspending agent etc ${ }^{(13)}$.

$>$ Mangifera indica gum: It is commonly known as mango belongs to the family Anacardiaceae. The appearance of the powder is in white to off-white in colour. It can be used as disintegrant, binder, suspending and emulsifying agents $^{(14)}$.

> Gum karaya: it is the exudate obtained from the trees belongs to the genus of Sterculia. It's made up of the following polysaccharides like galactose, rhamnose, and galacturonic acid. Gum karaya can be used as a superdisintegrant alternative to other superdisintegrants due to its low cost, biocompatibility etc ${ }^{(\mathbf{1 5})}$.

$>$ Locust bean gum (carob gum): It is the gum, which is obtained by the extraction of seeds of Ceratonia siliqua. It can be used as gelling agent, thickening agent and also bio-adhesive agent. It looks like yellowish- white, odourless powder ${ }^{(16)}$.

$>$ Mucilage of fenugreek seeds: Trigonella foenum-graceum is the plant which belongs to the family of Leguminosae. When the seeds expose to water mucilage will be forming a sticky mass. It showed good disintegrating property than the widely used superdisintegrant as Ac-di-sol ${ }^{(17)}$.

$>$ Plantago ovata mucilage: It is belonging to the family of Plantaginaceae. Which is widely used as superdisintegrant in the preparation of fast disintegrating tablets. Seeds and the husk contain highest percentage of mucilage.10-30\% of husk made up of hydrocolloids. The polysaccharides of xylose, galacturonic acid, galactose, rhamnose, and arabinose are responsible for disintegrating properties ${ }^{(\mathbf{1 8})}$.

$>$ Mucilage of Hibiscus rosa Sinensis: It belongs to the family of Malvaceae and is also known as shoe flower plant, China rose, and Chinese hibiscus. Thickeners, suspending agents, water retention agents, and disintegrants are all used with mucilage. Its leaves contain mucilage, which includes L-rhamnose, D-galactose, D-galacturonic acid etc ${ }^{(\mathbf{1 9})}$.

$>$ Dehydrated banana powder: The powder which is obtained from different varieties of banana known as ethan and nenthran. Which belongs to the family of Musaceae. Due to high amount of carbohydrate, it is a good source of energy ${ }^{(20)}$.

\section{CONCLUSION}

The superdisintegrants of natural origin provides predominant effects than synthetic superdisintegrants. The substances can be utilized as binder, diluent etc. The disintegrant property will be addressing them for the preparation of orodispersible tablets. Which will improve the patient compliance in a population who finds difficulty in swallowing. These substances give increased drug release and decrease the disintegration time. Moreover, it provides the advantages like nontoxic, easily available, low cost, biocompatible etc over synthetic substances. 
Acknowledgement: None

\section{Conflict of interest: None}

\section{Source of funding: None}

\section{REFERENCES}

1. Alam MT, Parvez N, Sharma PK. FDAApproved Natural Polymers for Fast Dissolving Tablets. Journal of Pharmaceutics. 2014 Apr 27;2014:95270.

2. Ratnaparkhi MP, Dr.G.P.Mohanta, Upadhyay DL. Review On: Fast Dissolving Tablet. Journal of Pharmacy Research. 2015 Feb 19;5-12.

3. Pahwa R, Gupta N. Superdisintegrants in the development of orally disintegrating tablets: A review. International Journal of Pharmaceutical Sciences and Research. 2010 Nov 30;2.

4. Gholve S, Kaware A, Thonte S, Kaudewar D, Bhusnure DrO. Orodispersible tables: a systematic review. world journal of pharmaceutical sciences. 2018 Apr 13;7(6):152-65.

5. Gandhi L, Akhtar S. Comparative study on effect of natural and synthetic superdisintegrants in the formulation of orodispersible tablets. Journal of Drug Delivery and Therapeutics. 2019 Mar 15;9(2):507-13.

6. Beneke CE, Viljoen AM, Hamman JH. Polymeric Plant-derived Excipients in Drug Delivery. Molecules. 2009 Jul;14(7): 2602-20.

7. Singh A, Gupta N, Gupta A. A review on herbal excipients. International Journal of Indigenous Herbs and Drugs. 2021 Feb 15;05-8.

8. Anand N, Singh DRL, Sharma D. Emergence of natural superdisintegrants in oro-dispersible tablets: An overview. International Journal of Current Pharmaceutical Research. 2013 Apr 1;4:33-8.

9. Malviya R, Srivastava P, Bansal M, Sharma P. Mango peel pectin as superdisintegrating agent. Journal of Scientific \& Industrial Research. 2010 Oct 1;69:688-90.
10. Goel H, Kaur G, Tiwary A, Rana V. Formulation Development of Stronger and Quick Disintegrating Tablets: A Crucial Effect of Chitin. Yakugaku zasshi : Journal of the Pharmaceutical Society of Japan. 2010 May 1;130:729-35.

11. Madhulika GSSV, Kuber BR. A review on natural and synthetic polymers employed in the formulation of oral disintegrating tablets. Journal of Drug Delivery and Therapeutics. 2019 Apr 15;9(2-s):652-8.

12. Hosny KM, Mosli HA, Hassan AH. Soy polysaccharide as a novel superdisintegrant in sildenafil citrate sublingual tablets: preparation, characterization, and in vivo evaluation. Drug Des Devel Ther. 2015 Jan 12;9:46572.

13. Rowe R, Sheskey PJ, Quinn ME. Handbook of pharmaceutical excipients. Sixth. RPS; 2009. 1-888 p.

14. Nayak RK, Patil SR, Patil MB, Bhat M. Evaluation of disintegrating properties Of Mangifera indica gum. RGUHS Journal of Pharmaceutical Sciences. 2011;1:11-21.

15. Shirwaikar A, Shirwaikar A, Prabu SL, Kumar GA. Herbal Excipients in Novel Drug Delivery Systems. Indian J Pharm Sci. 2008;70(4):415-22.

16. Malik K, Arora G, Singh I. Locust bean Gum as Superdisintegrant- Formulation and Evaluation of Nimesulide Orodispersible Tablets. Polimery w medycynie. 2011 Jan 1;41:17-28.

17. Kumar R, Patil S, Patil M, Patil S, Paschapur M, Parade M. Isolation and Evaluation of Disintegrant Properties of Fenugreek Seed Mucilage. International Journal of PharmTech Research. 2009 Oct 1;1:982-96.

18. Draksiene G, Kopustinskiene DM, Lazauskas R, Bernatoniene J. Psyllium (Plantago Ovata Forsk) Husk Powder as a Natural Superdisintegrant for Orodispersible Formulations: A Study on Meloxicam Tablets. Molecules. 2019 Jan;24(18):3255.

19. Prabhu K, Shaista O, Rajanna S, Pranesh K. Formulation And Evaluation Of Mouth Disintegrating Tablets Of Famotidine By Using Hibiscus Rosa - Sinensis Mucilage 
And Treated Agar. International Journal of Research in Ayurveda and Pharmacy. 2010;1:497-505.

20. Prabakaran L, Sendhil D. Formulation development of patient friendly dosage form: All in one natural excipient as binder, diluent and disintegrant. International Journal of Pharmacy and
Pharmaceutical Sciences. 2011 Mar 1;3: 97-102.

How to cite this article: Femi Joseph, K. Premaletha. Natural superdisintegrants for the formulation of orally disintegrating tablets. International Journal of Research and Review. 2021; 8(11): 123-128. DOI: https:// doi.org/10.52403/ijrr.20211117 